\title{
Safe approach in "All-on-four" technique: a case report
}

\author{
Marouene Ben Hadj Hassine, DDS 1 \\ Paolo Bucci, MD, DDS 2 \\ Roberta Gasparro, DDS, PhD 2 \\ Alessandro Espedito Di Lauro, DDS ${ }^{2}$ \\ Gilberto Sammartino, MD, DDS \\ ${ }^{1}$ Department of Oral Medicine and Oral Surgery, Uni-
versity of Dental Medicine, Monastir, Tunisia
2 University of Naples Federico II, Italy
}

Corresponding author:

Gilberto Sammartino, MD, DDS

Federico II University

Via Pausini, 5

80131 Napoli, Italy

E-mail: gilberto.sammartino@unima.it

\section{Summary}

The "All-on-Four" concept is based on the placement of four implants in the anterior part of fully edentulous jaws to support a provisional, fixed, and immediately loaded full-arch prosthesis. Combining tilted and straight implants for supporting fixed prostheses can be considered a viable treatment modality resulting in a more simple and less time consuming procedure, in significantly less morbidity, in decreased financial costs and a more comfortable postsurgical period for the patients. The authors present a case report with mandibular atrophy and left mental foramina on the top of the residual crest.

Key words: edentulous jaw, dental implants, implant placement.

\section{Introduction}

Current standards in implant dentistry are intended to provide prosthetic restorations with the finest esthetic and functional outcomes. Several parameters have been suggested to achieve gold standard results: adequate bone height, width and sagittal projection, adequate soft tissue quantity and quality, preservation of buccal sulcus and adequate papillae and gingival contour (1) .

Solutions to inadequate ridge height include the use of short implants (2), vertical ridge augmentation procedures $(3,4)$, or cantilever prostheses (5). Although having a comparable short-term survival rate, some authors state that the long-term performance of short implants is less understood, especially in the posterior maxilla with lower bone density (6). Vertical augmentation procedures increase patient morbidity and the outcome is less predictable, mainly in the posterior mandible. Cantilever prostheses might incur higher rates of prosthetic complications such as abutment loosening, denture fracture and implant failure.

Due to the less predictable long-term prognosis associated with the above mentioned procedures, the "Allon-Four" technique was proposed for the rehabilitation in edentulous jaws. The "All-on-Four" concept is based on the placement off our implants (two axial and two tilted implants) in the anterior part of fully edentulous jaws to support a provisional, fixed, and immediately loaded full-arch prosthesis.

Combining tilted and straight implants for supporting fixed prostheses can be considered a viable treatment modality (7) resulting in a more simple and less time consuming procedure, in significantly less morbidity, in decreased financial costs and a more comfortable postsurgical period for the patients (8).

\section{Case presentation}

A 58-year-old man, edentulous for a long period of time due to periodontal disease, was referred to the Department of Oral Surgery-University of Naples Federico II, Italy, requiring a fixed prosthetic rehabilitation in the lower jaw. His past medical history was uneventful (Fig. 1).

The panoramic radiograph revealed an advanced alveolar bone resorption, particularly in the mandible (Fig. 2). The Ct scan confirmed the mandibular atrophy and showed the left mental foramina on the top of the residual crest (Fig. 3).

The "All-on-Four" technique was scheduled to rehabilitate the lower jaw.

Under local anesthesia, a full thickness crestal incision was performed from the right first molar region to the left first premolar one. A midline releasing incision was carried out to facilitate flap reflection and to identify the left mental nerve emergence (Fig. 4). The 2 $\mathrm{mm}$ osteotomy was made in the midline position and the guide was placed (Fig. 5). The vertical lines on the guide were used as a reference to prepare the implant sites in the correct position, with an angulation which should not exceed $45^{\circ}$. All sites were prepared using the manufacturer's guidelines (Tekka Inkone $\left.{ }^{\circledR}\right)$, under copious sterile saline irrigation. A control of a possible communication between implant sites was done before implant placement. 
The two anterior implants (Tekka In-kone $®)$ were placed in the incisive area, whereas the two posterior implants were placed, following the diagonal of the rectangle (Fig. 6 ), at an angle of $30^{\circ}$ mesially to the mental foramina. After soft tissue management and closure, straight and angulated abutments were placed onto the implants (Fig. 7) and the multiunit impression copings were attached to the prosthetic abutments and splinted using wire-bars and low shrinkage autopolymerizing resin (Fig. 8) to ensure an accurate transfer with- out accidental displacement, when an alginate impression was taken.

The polyvinylsiloxane impression of the complete removable prosthesis was made to detect the position of implants and soft tissue.

The definitive, immediate loaded prosthesis was given to the patient after 24 hours (Fig. 9).

The panoramic radiograph at 1-year-follow up revealed a good bone healing and no sign of bone resorption around implant shoulders (Fig. 10).

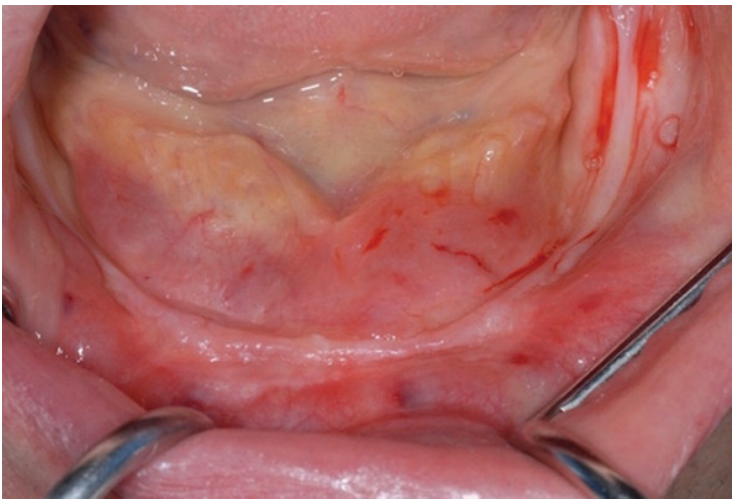

Figure 1. Preoperative clinical view.

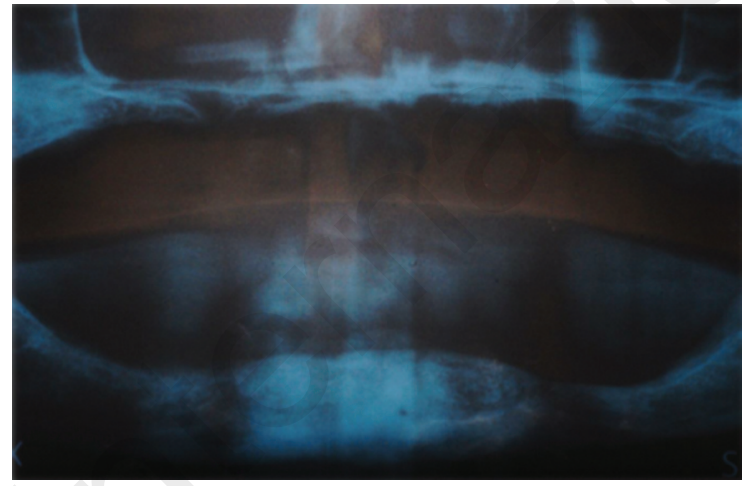

Figure 2. Preoperative panoramic radiograph.

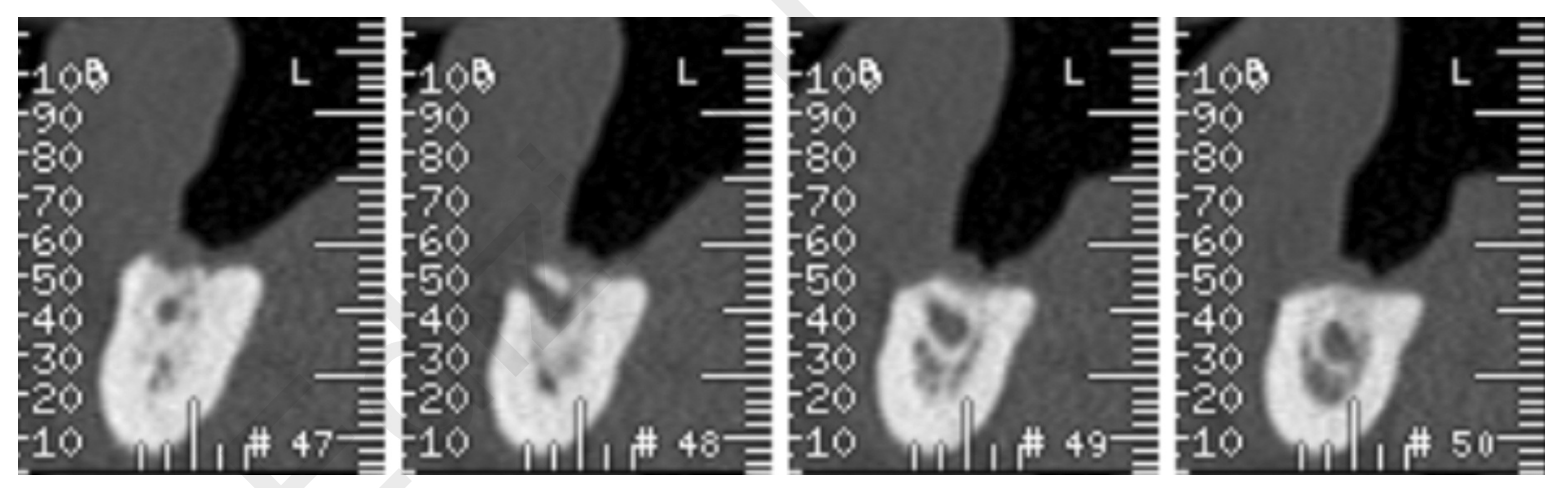

Figure 3. CT Scan showing the crestal position of the left mental nerve.

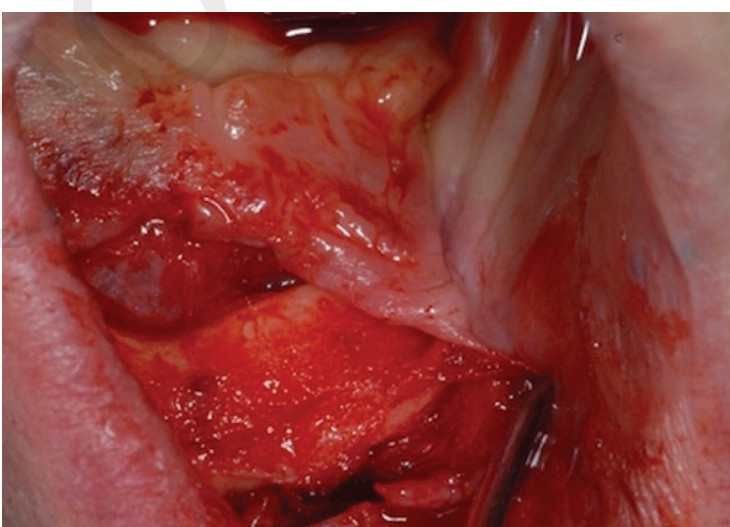

Figure 4. Identification of the mental nerve: (left side).

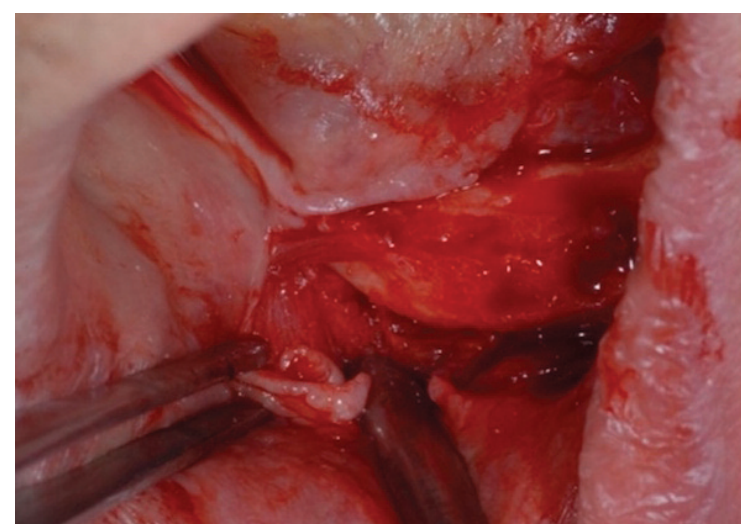

Figure 5. Identification of the mental nerve: (right side). 


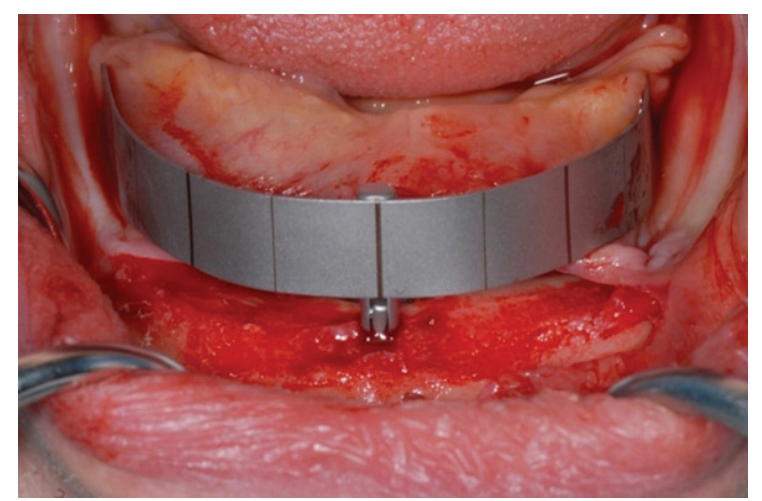

Figure 6. Placement of the mandibular guide.

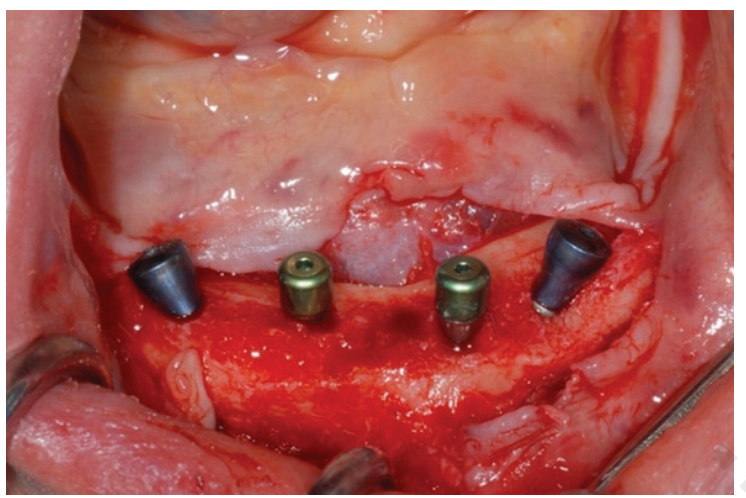

Figure 7. Preparation of the distal implant site.

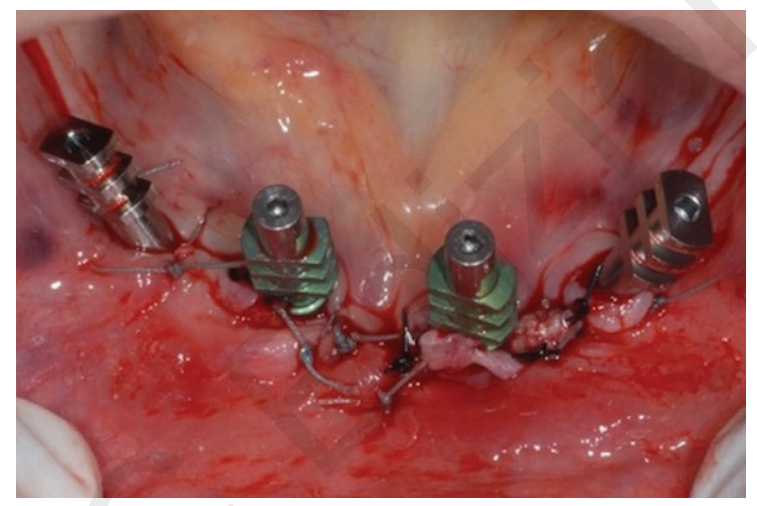

Figure 8. Placement of straight and angulated abutments.

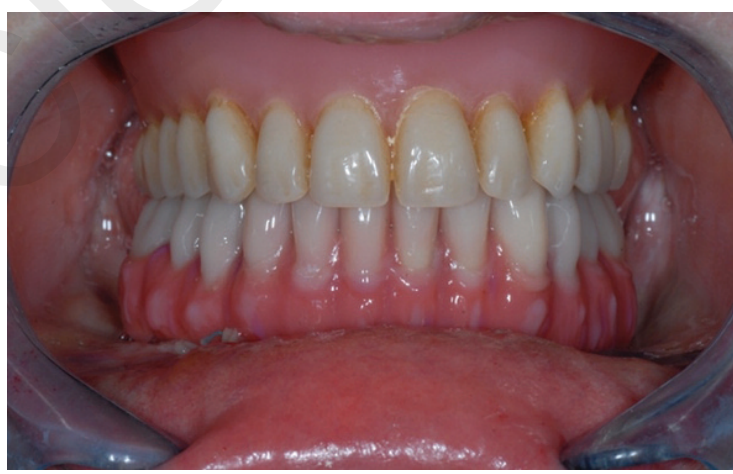

Figure 9. The definitive prosthesis.

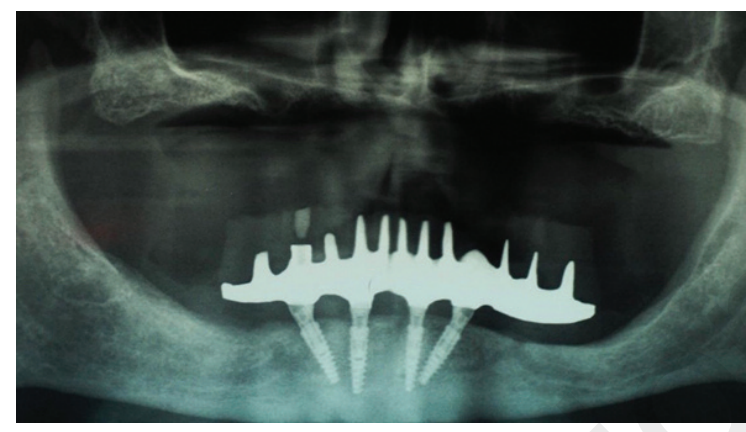

Figure 10. Panoramic radiograph after 1-year-follow-up.

\section{Discussion}

A recent shift in practice paradigm has been to minimize treatment costs and patient morbidity while providing the most satisfying patient-centered treatment outcomes according to the state of the art of dental practice. The "Allon-Four" treatment concept is an attempt to reach these objectives by providing relatively straight forward, predictable treatment option to rehabilitate edentulous patients with a high outcome of quality of life (9).

In this technique, the placement of the two posterior implants in front of mental foramina and tilted with a distal direction avoids to injure the inferior alveolar nerve and decreases the cantilevers, allowing the increase of the polygonal area for a full fixed prosthesis and providing satisfactory molar support $(10,11)$. According to Krekmanov et al., the gained mean distance of prosthesis support in the mandible is $6,5 \mathrm{~mm}$ while it is $9,3 \mathrm{~mm}$ in the maxilla (12). The "All-onFour" procedure also improves cortical anchorage and primary stability, allowing the use of longer implants. In a three-dimensional finite element analysis about load transmission using different implant inclinations and cantilever lengths, Bevilacqua et al. reported a reduction of stress around anterior implants in a full fixed prosthesis design, when tilted implants were compared to straight implants (13).

Furthermore there are no significant differences between axial and tilted implants in terms of success rates and marginal bone loss (14).

In the present case report, the crestal position of the mental nerve requested to change the flap design with respect to the surgical protocol, which consists of a linear incision performed from the first molar to the contralateral one, with or without two vertical distal incisions. The midline releasing incision allowed an easier reflection of the flap, a less difficult implant placement and nerve injury preservation.

The bone growth around the implant shoulders might be justified by the subcrestal position and the implant characteristics, such as platform switching and a morse taper connection. Moreover, the microstructured surface texture extended onto the implant shoulder seems to play a role in minimizing the marginal bone loss $(0.11 \mathrm{~mm}, 0.08 \mathrm{~mm})$ and in promoting bone formation on the implant platform, even when using tilted implants $(15,16)$. 


\section{Conclusion}

The "All-on-4" treatment concept seems to be an alternative option for rehabilitating edentulous jaws compared with advanced surgical approaches without using removable prostheses. It is a cost-effective procedure, decreasing the treatment times, the morbidity and allowing a higher patient quality of life.

Marginal bone loss around splinted tilted implants to support full-arch fixed prosthesis doesn't significantly differ from straight implants in short and mediumterm. Nevertheless, long-term results are required to verify this finding. Furthermore, platform switching, morse taper connection and microstructured surface texture extended onto the implant shoulder seem to play a role in stabilizing the peri-implant bone, also when tilted implants are used.

\section{References}

1. Guerrero C, Lopez P, Figueroa F, et al. Three-dimensional alveolar distraction osteogenesis. In: Bell W, Guerrero C, editors. Distraction osteogenesis of the facial skeleton. 1st edition. Hamilton (Canada): BC Decker, 2007; 457-93.

2. Esposito M, Grusovin MG, Coulthard P, Worthington HV. The efficacy of various bone augmentation procedures for dental implants. A Cochrane systematic review of randomized controlled clinical trials. Int $\mathrm{J}$ oral Maxillofac Implants. 2006;21:696-710.

3. Sorní M, Guarinós J, García O, Peñarrocha M. Implant rehabilitation of the atrophic upper jaw: a review of the literature since 1999. Med Oral Patol Oral Cir Bucal. 2005;10 Suppl 1:E45-56.

4. Maestre-Ferrín L, Boronat-Lopez A, Penarrocha-Diago M, et al. Augmentation procedures for deficient edentulous ridges, using on lay autologous grafts: An update. Med Oral Patol Oral Cir Bucal. 2009;14:402.

5. Chaushu G, Mardinger O, Peleg M, et al. Analysis of com- plications following augmentation with cancellous block allografts. J Periodontol. 2010;81:1759.

6. Hashemi HM. Neurosensory function following mandibular nerve lateralization for placement of implants. Int J Oral Maxillofac Surg. 2010; 39:452.

7. Vega LG, Bilbao A. Alveolar distraction osteogenesis for dental implant preparation: An update. Oral Maxillofac Surg Clin North Am. 2010;22:369.

8. Peñarrocha Diago M, Maestre Ferrín L, Peñarrocha Oltra D, Canullo L, Calvo Guirado JL, Peñarrocha Diago M. Tilted implants for the restoration of posterior mandibles with horizontal atrophy. An alternative treatment. J oral Maxillofac Surg. 2013;71.856-864.

9. Rangert B, Jemt T, Jörneus L. Forces and moments on Brånemark implants. Int J Oral Maxillofac Implants. 1989;4:241-247.

10. Sertgöz A, Güvener S. Finite element analysis of the effect of cantilever and implant length on stress distribution in an implant-supported fixed prosthesis. J Prosthet Dent. 1996;76:165-169.

11. Butura CC, Galindo DF, Jensen OT. Mandibular all-on-four therapy using angled implants: a three-year clinical study of 857 implants in 219 jaws. Oral Maxillofac Surg Clin North Am. 2011 May;23(2):289-300.

12. Malo P, Rangert B, Nobre M. "All-on-four" immediate-function concept with Branemark system implants for completely edentulous mandible: A retrospective clinical study. Clin Implant Dent Relat Res. 2003;5:2.

13. De Vico G, Bonino M, Spinelli D, Schiavetti R, Sannino G, Pozzi A, Ottria L. Rationale for tilted implants: FEA considerations and clinical reports. Oral Implantol (Rome). 2011 Jul;4(3-4):23-33.

14. Krekmanov L, Kahn M, Rangert B, Lindstrom $H$. Tilting of posterior mandibular and maxillary implants of improved prosthesis support. Int J Oral Maxillofac Implants. 2000;15:405414.

15. Bevilacqua M, Tealdo T, Pera F, et al. Three-dimensional finite element analysis of load transmission using different implant inclinations and cantilever lengths. Int J Prosthodont. 2008; 21:539-542.

16. Gowgiel JM. The position and course of the mandibular canal. J Oral Implantol. 1992;18:383. 